\title{
Immunomodulatory Activities of a Concentrated Fruit and Vegetable Juice Tested in a Randomized, Placebo-Controlled, Double-Blind Clinical Trial in Healthy Volunteers
}

\author{
Manfred Schmolz ${ }^{1}$, Reinhard W. März ${ }^{2,3}$, Marco Schaudt ${ }^{4}$, Cornelia Schaudt ${ }^{4}$, Carola Lauster ${ }^{4}$ \\ ${ }^{1}$ EDI GmbH, Reutlingen, Germany; ${ }^{2}$ SCIRM, Fürth, Germany; ${ }^{3}$ Technische Hochschule, Nuremberg, Germany; ${ }^{4}$ analyze \& realize \\ GmbH, Berlin, Germany. \\ Email: mschaudt@analyze-realize.com
}

Received November $4^{\text {th }}, 2013$; revised December $4^{\text {th }}, 2013$; accepted December $11^{\text {th }}, 2013$

Copyright (C) 2014 Manfred Schmolz et al. This is an open access article distributed under the Creative Commons Attribution License, which permits unrestricted use, distribution, and reproduction in any medium, provided the original work is properly cited. In accordance of the Creative Commons Attribution License all Copyrights (C) 2014 are reserved for SCIRP and the owner of the intellectual property Manfred Schmolz et al. All Copyright (C) 2014 are guarded by law and by SCIRP as a guardian.

\begin{abstract}
22 healthy volunteers were included in a randomized, placebo-controlled pilot study in order to investigate immunomodulatory effects of a concentrated juice, containing the ingredients of a total of 80 different fruits, vegetables, herbs, mushrooms, oils, and others (Cellagon aurum ${ }^{\circledR}$, “CA”). 11 subjects received the concentrated juice while 11 were allocated to the placebo group. Stimulated whole-blood cultures were used to assess any treatment-related changes in the response of leukocytes towards experimental immune cell activation. For each of the individuals, 5 cultures were performed either immediately before, during, or $\mathbf{3}$ days after termination of the 7 weeks treatment. Leukocyte activities were determined by measuring cytokine levels in the supernatants at the end of the $48 \mathrm{~h}$ of stimulation (induced by the addition of LPS + SE-B + anti-CD28 antibodies). Despite the relatively small number of volunteers, multiplexed cytokine assays revealed a typical T-cell signature of cytokines that were increased significantly in the course of CA treatment compared to placebo (GM-CSF, IFN $\gamma$, IL-4, IL-10, IL-17, TNF $\beta$, all $p<0.05$ ). These preliminary results suggest that CA is able to support leukocyte activation, in particular that of T-lymphocytes.
\end{abstract}

\section{KEYWORDS}

\section{Randomized Placebo-Controlled Clinical Trial; Ex Vivo; Cytokine; Juice Concentrate}

\section{Introduction}

Herbs, vegetables and fruits have been investigated intensely with regard to protective effects they may provide to human tissues. Many of their activities were found to be related to oxygen radical scavenging (reviewed for example by [1]), although the clinical benefit of this kind of food ingredients was questioned by others [2]. Some of these radical scavengers, but also numerous other substances from herbs, vegetables and fruits were found to have anti-inflammatory effects (e.g. [3,4]). Less well characterized are those drugs with so-called immunomodulatory ingredients, which are usually presumed to be major constituents of herbal remedies, such as Cone flower (Echinacea). Immunomodulation characterizes substance effects that are able to support either, or dampen immune cell activities, a rather old concept that experienced considerable appreciation in the past decade, especially in the treatment of more complex diseases, like autoaggressive disorders $[5,6]$.

The clinical study presented in this paper was designed to address the question of whether Cellagon aurum ${ }^{\circledR}$ (CA) does affect immune cell activities in vivo. CA is a concentrated juice consisting of 80 different natural products (Table 1), such as fruit juices, extracts from vegetables, mushrooms, and herb, but also different oils, as well as micronutrients (such as calcium, iron, coenzyme $\mathrm{Q}_{10}$, 
Table 1. Nutritional values of Cellagon aurum.

\begin{tabular}{|c|c|c|}
\hline Nutritional values & $\begin{array}{l}\text { Intake per day by } 20 \mathrm{ml} \\
\text { CA in } 260 \text { ml water }\end{array}$ & $\% \mathrm{RDI}$ \\
\hline Caloric value kj/kcal & $150 / 35$ & \\
\hline Protein g & 0.7 & \\
\hline Total carbohydrates g & 5.0 & \\
\hline Sugar g & 3.6 & \\
\hline Total fat fat $g$ & 0.5 & \\
\hline Saturated fatty acids $g$ & 0.1 & \\
\hline Polyunsaturated fatty acids g & 0.3 & \\
\hline Fibers $g$ & 3.0 & \\
\hline Sodium g & 0.008 & \\
\hline \multicolumn{3}{|l|}{ Vitamins } \\
\hline Vitamin C mg & 120 & 150 \\
\hline Vitamin E mg & 18 & 150 \\
\hline Niacin mg & 12 & 75 \\
\hline Pantothenic acid mg & 9 & 150 \\
\hline Vitamin B6 mg & 2.1 & 150 \\
\hline Vitamin B2 mg & 2.1 & 150 \\
\hline Vitamin B1 mg & 1.7 & 150 \\
\hline Folic acid $\mu g$ & 200 & 100 \\
\hline Biotin $\mu \mathrm{g}$ & 75 & 150 \\
\hline Vitamin B12 $\mu \mathrm{g}$ & 3.8 & 150 \\
\hline \multicolumn{3}{|l|}{ Minerals } \\
\hline Calcium mg & - & - \\
\hline Iron mg & 4.2 & 30 \\
\hline Magnesium mg & 56 & 15 \\
\hline Zink mg & 3.0 & 30 \\
\hline Manganese mg & 0.60 & 30 \\
\hline Copper mg & 0.15 & 15 \\
\hline Selene $\mu \mathrm{g}$ & 8.3 & 15 \\
\hline Chrome $\mu \mathrm{g}$ & 6.0 & 15 \\
\hline Molybdenum $\mu g$ & 7.5 & 15 \\
\hline
\end{tabular}

lecithin, or L-carnitine). Given the complexity of this preparation and the fact that at least some of its constituents are well-known to contain substances with immu- nomodulating activities e.g. chamomile [7,8], hops [9], grape seeds [10], broccoli [11], vitamins [12-17], etc., this study aimed specifically at testing changes in immune cell function during CA intake. For this purpose the TruCulture ${ }^{\circledR}$ test system was chosen, because it enables the testing of leukocyte activities ex vivo, i.e.: after these cells were exposed to the biologically active ingredients of CA in vivo [18]. The TruCulture ${ }^{\circledR}$ test system is based on "bed-side cell cultures" and therefore avoids numerous artifacts common to other assays testing leukocyte function. This is achieved by cultivating peripheral blood immune cells directly in the syringe used to draw the blood, i.e. in their natural environment (wholeblood). Hence, these cultures can be set up without any delay between the blood draw and starting these cultures. Moreover, the examination of immune cell activities can be performed without the usual preparation of leukocytes, what otherwise would have introduced further cell stress. And finally, the inter-assay variability is reduced to a minimum, because the complete procedure consists of just one step, i.e.: the blood draw. This makes it possible to obtain reliable results with rather low numbers of trial subjects.

The cells were incubated in these syringe-tubes under stimulating conditions, mimicking the presence of bacterial infection: bacterial lipopolysaccharide (LPS, stimulating cells of the innate immune response; [19]) was combined with staphylococcal enterotoxin-B (SE-B, activates T-lymphocytes in an antigen-specific manner, while involving innate antigen-presenting cells; [20]), plus antibodies against CD28, a surface molecule that is required for potent upregulation of T-cell activities [21]. This type of activation represents a broad, physiologically relevant trigger of defense responses of immune cells.

\section{Material and Methods}

\subsection{Study Design}

This nutrition study was conducted as an explorative, mono-centric, randomized, double-blind, placebo-controlled study in healthy outpatient subjects in Berlin (Germany) between August and December 2012. The effect of Cellagon aurum ${ }^{\circledR}$ (CA) on treatment-related changes in the response of leukocytes (ex vivo cytokine expression) was compared to placebo. The study was approved by the Ethics Committee of the Charité, Berlin (Germany) and was carried out in accordance with the declaration of Helsinki/Hong Kong 1989/Somerset 1996 as well as the ICH-GCP guidelines (CPMP/ICH/135/95).

\subsection{Study Population and Treatment}

Twenty-two healthy subjects were included in this study. They had to meet the following inclusion criteria: age 
between 18 - 40 years, nonsmokers with a good general state of health, and written consent to participate. The main exclusion criteria were as follows: any type of acute or chronic diseases or known allergies, vaccination or surgery within the last 6 months before or during the clinical trial, intake of any supplements, pre-/probiotics or drugs known to influence the immune system 14 days (d) before and during the investigation, known sensibility to one of the ingredients of the study product, as well as pregnancy or nursing.

CA is a concentrate made of 80 ingredients (HansGünter Berner GmbH \& Co. KG, Germany), the corresponding placebo, identical in appearance, was a fruit juice concentrate containing orange and apple juice, mineral water, fructose, apple extract, citric acid, potassium sorbate, sucralose sweetener, beta-carotene and carmine, natural flavors without any additional vitamins or minerals, comparable in caloric value to CA (Hans-Günter Berner GmbH \& Co. KG, Germany).

Subjects were randomly assigned to receive CA or placebo. The study participants were instructed to take two times daily $10 \mathrm{ml}$ of CA or the corresponding placebo, mixed with $120 \mathrm{ml}$ drinking water or mineral water preferred at breakfast and dinner over a period of 7 weeks.

Twenty-two subjects met the inclusion criteria and did not violate the exclusion criteria and were randomized into this nutritional trial. Two of the 22 participants were excluded from the study at V3 (one: elevated CRP-values due to sunburn; one: venous disease). From these participants no efficacy values from V4 and V5 are available, therefore they were exclude from the full analysis set (FAS) population. Thus 20 subjects represent the FAS population (see Figure 1). Since all of them adhered to the study protocol they represent the valid case analysis set (VCAS).

Of the 20 subjects of the FAS population 13 were woman and 7 men. All the study participants were classified as Caucasian. With respect to baseline characteristics, there were no statistically significant differences between the two study groups (Table 2).

During the study period, five visits (see Table 3: V1screening, V2-randomization and dispensation of the investigational product; V3 — at the fourth day of intake of the investigational product; first TruCulture ${ }^{\circledR}$ from blood cells; V4-after $14 \mathrm{~d}$ of intake of the investigational product; second TruCulture ${ }^{\circledR}$ from blood cells; V5-final visit at day $56 \pm 2$ and $3 \mathrm{~d}$ after the last intake of the investigational product; third TruCulture ${ }^{\circledR}$ from blood cells) were performed in the practice of the investigator.

\subsection{Outcome Measures}

Ex Vivo TruCulture ${ }^{\circledR}$ tests

The TruCulture ${ }^{\circledR}$ test system consists of a closed syringe-tube, described in detail elsewhere [18]. In brief, the blood is drawn into these tubes, containing a proprietary culture medium, supplemented with the experimental stimulants LPS (from E. coli, O55: B5; Calbiochem,

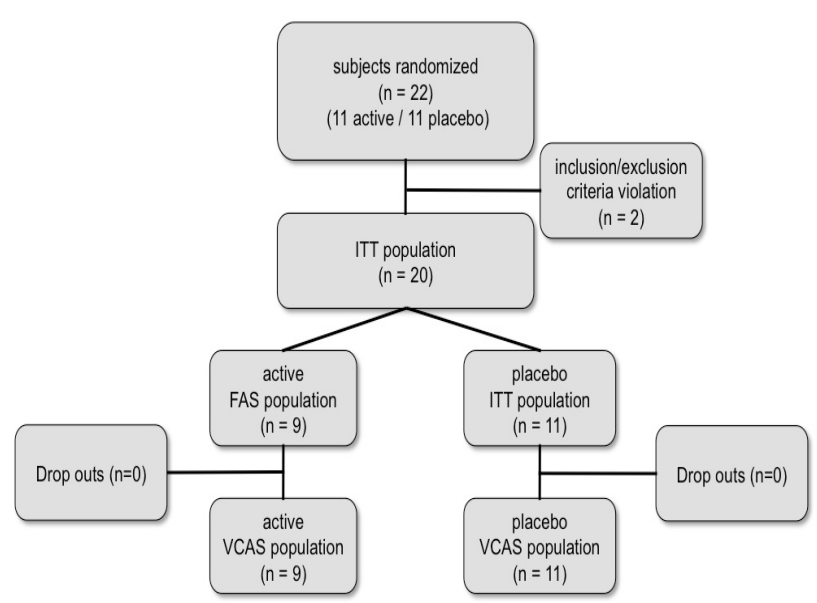

Figure 1. Flow chart of the study population.

Table 2. Mean ( \pm SD) baseline characteristics of the study population.

\begin{tabular}{cccc}
\hline \multicolumn{4}{c}{ Study population } \\
\hline & CA $(\mathrm{n}=9)$ & Placebo $(\mathrm{n}=11)$ & $p$-value \\
\hline Age (years) & $27.9 \pm 5.7$ & $32.7 \pm 6.9$ & 0.107 \\
Sex $(\mathrm{m} / \mathrm{f})$ & $3 / 6$ & $4 / 7$ & 1.0 \\
Height $(\mathrm{cm})$ & $173.1 \pm 7.2$ & $170.4 \pm 8.7$ & 0.467 \\
Body weight $(\mathrm{kg})$ & $67.9 \pm 7.5$ & $62.0 \pm 7.9$ & 0.131 \\
BMI kg/m & $22.6 \pm 1.5$ & $21.3 \pm 1.7$ & 0.070 \\
\hline
\end{tabular}

Table 3. Study course.

\begin{tabular}{|c|c|c|c|c|c|c|}
\hline Visit purpose & V1 (1 - 7 d before V2) & V2 (d 0) & V3 (d 4) & $\mathrm{V} 4(\mathrm{~d} 14 \pm 2)$ & & V5 (d $56 \pm 2)$ \\
\hline & Screening & $\begin{array}{c}\text { Inclusion Dispensation: } \\
\text { CA Placebo }\end{array}$ & Control \# & Control \#2 & $\begin{array}{l}\text { End of ingestion } \\
\text { after } 53 \text { days }\end{array}$ & Control \#3 End of study \\
\hline Blood & $\mathrm{X}$ & $\mathrm{X}$ & $\mathrm{X}$ & $\mathrm{X}$ & & $\mathrm{X}$ \\
\hline TruCulture $^{\circledR}$ & & Baseline & $\# 1$ & $\# 2$ & & $\# 3$ \\
\hline Urine & $\mathrm{X}$ & $\mathrm{X}$ & $\mathrm{X}$ & $\mathrm{X}$ & & $\mathrm{X}$ \\
\hline
\end{tabular}


Germany), SE-B (from S. aureus; Bernhard-Nocht-Institute, Germany), as well as anti-CD28 antibodies (Beckmann-Coulter, Germany). Within 15 min from the blood draw, the plungers of these syringe tubes were broken away and the tubes were transferred into a dry-block thermostat (VLM GmbH, Germany), where they were incubated for a total of $48 \mathrm{~h}$ at $37^{\circ} \mathrm{C}$. Then the culture supernatants were harvested and stored below $-18^{\circ} \mathrm{C}$ until shipping on dry ice to EDI GmbH, where they were kept below $-18^{\circ} \mathrm{C}$ until testing cytokine concentrations, without any interruptions of the cold chain.

\section{Cytokine Assays}

Multiplexed analyte profiles (MAP, Myriad RBM, Austin TX, USA) were used to determine the concentrations of cytokines, chemokines, growth factors, and other leukocyte activation markers in the supernatants of the TruCulture $^{\circledR}$ whole-blood cultures. In brief: Upon arrival at EDI $\mathrm{GmbH}$, all samples were stored at $-80^{\circ} \mathrm{C}$ until tested. The mixture of sample and capture microspheres were thoroughly mixed and incubated at room temperature for 1 hour. Multiplexed cocktails of biotinylated reporter antibodies for each multiplex were then added and incubated for an additional hour at room temperature. Multiplexes were developed using an excess of streptavidin-phycoerythrin solution. Analysis was performed in a Luminex 100/200 instrument and the resulting data stream was interpreted using proprietary data analysis software developed at Rules-Based Medicine. Unknown values for each of the analytes localized in a specific multiplex were determined using 4 and 5 parameter, weighted and non-weighted curve fitting algorithms included in the data analysis package.

The panel of activation markers, shown in Table 4 was measured from these samples.

Safety and Tolerability

As concurrent variables the tolerability of the investi-

Table 4. Measured markers.

\begin{tabular}{cccc}
\hline \multicolumn{2}{c}{ HumanCytokine MAP A* } & \multicolumn{2}{c}{ HumanCytokine MAP B $^{*}$} \\
\hline GM-CSF & IL-8 & BDNF & IL-15 \\
IFN- $\gamma$ & IL-10 & Eotaxin & IL-17 \\
IL-2 & MCP-1 & ICAM-1 & IL-23 \\
IL-3 & MIP-1 $\alpha$ & IL-1 $\alpha$ & MMP-3 \\
IL-4 & MIP-1 $\beta$ & IL-1 $\beta$ & SCF \\
IL-5 & TNF $\alpha$ & IL-1ra & VEGF \\
IL-6 & TNF $\beta$ & IL-12p40 & \\
IL-7 & & IL-12p70 & \\
\hline
\end{tabular}

*List of abbreviations: see supplementary data. gational product was evaluated by both the subjects and the investigators at the end of the study. The following ratings were used for it: "very good" "good", "moderate" or "poor". The safety and tolerability of the product was additionally evaluated by the documentation of adverse events.

\subsection{Statistical Evaluation}

The data were supplied by EDI GmbH, the provider of the cytokine assay as raw data. Statistical analysis was performed with SYSTAT (V 12.0, Systat Software Inc.).

Cytokines exhibit high inter-individual differences together with remarkable intra-individual long-term stability $[18,22]$. Also in this study, cytokines of the individual with the lowest values and the one with the highest value differed by factors between 3 (IL-10) and 1072 (IL-2). Neither parametric nor non-parametric methods can handle such differences sufficiently. Individual z-standardization is normally used in such situations, but for this purpose at last 5 values without treatment influence are needed for each individual, which was not possible for this exploratory or a proof-of-concept-study. Thus, for the comparison of the groups, we calculated the differences between the visits \#2 (baseline, immediately before starting the treatment) and \#3 (after 3 days of treatment = labelled "acute" effects in the graphs below), visits \#2 and \#4 (2 weeks of treatment $=$ " 2 wks"), and visits \#4 and \#5 (2 - 4 days after ending the treatment = "EOTrtmt”) for each individual and tested these variables with a t-test for independent samples, along with a MannWhitney-U-Test as a back-up in case of major differences in the variances between the groups, which had to expected.

From all cytokines determined in this study, GM-CSF, IFN $\gamma$, IL-2, IL-4, IL-10, IL-17 and TNF $\beta$ were selected for closer analysis based on a first graphical evaluation of the time course of all individuals.

\section{Results}

No drop-outs due to undesired events occurred during the observation phase of this clinical study. 11 of the 11 subjects from the placebo group and 9 out of 11 from the active treatment group finished the trial with a sufficient number of visits and data points to allow a proper statistical evaluation of their results.

\subsection{Cytokine Response}

As could be expected, not all cytokines responded equally well to the treatment. Compared to baseline, no notable changes during CA intake could be observed for the following parameters (data not shown in this paper): IL-3, BDNF, Eotaxin, Factor VII, ICAM-1, IL-7, IL-15, 
MMP-3, SCF, VEGF.

For a series of other functional endpoints changes were observed for just one or very few subjects only (IL$1 \alpha$, IL-1 $\beta$, IL-1ra, IL-5, IL-6, IL-8, IL-12p40, IL-12p70, IL-18, IL-23, MIP-1 $\alpha$, MIP-1 $\beta$, MCP-1, TGF $\beta$, TNF $\alpha$ ). However, as this occurred in both treatment groups (CA and placebo), it was not possible to reliably differentiate treatment-specific effects from random shifts in cellular activities (e.g. due to minor environmental challenges in some individuals, which must be considered a normal phenomenon in healthy persons). Also these results will not be shown in this paper.
On the other hand, six parameters were modulated more consistently (GM-CSF, IFN $\gamma$, IL-4, IL-10, IL-17, as well as $\operatorname{TNF} \beta$ ). These reached statistically significant differences either between the treatment groups after 3 days of CA ingestion (no such difference was detected between these two groups at baseline), and/or as differences within the CA group when comparing visit \#2 (baseline immediately before starting CA intake) to visit \#3 (after 3 days of treatment); no obvious change in the course of treatment was detected in the placebo group. These results are shown below in more detail (see Figures 2 and 3).

\begin{tabular}{|c|c|c|c|}
\hline Changes from & a) GM-CSF (Test for unpaired samples) & b) $\mathbf{I F N} \gamma$ (Test for unpaired samples) & c) IL-4 (Test for unpaired samples) \\
\hline visit \#2 to visit \#3 & $\begin{array}{c}{ }^{6} \text { Count }^{3} \\
\text { t-Test: } \mathrm{p}=0.053 \text { count }{ }^{6} \\
\text { MWU-Test: } \mathrm{p}=0.021 \uparrow\end{array}$ & 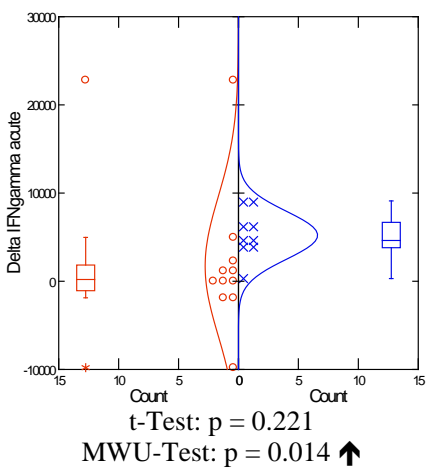 & $\begin{array}{l}{ }^{10} \text { count }^{5}{ }_{0}{ }^{5} \text { count }^{10} \\
\text { t-Test: } p=0.045 \uparrow \\
\text { MWU-Test: } \mathrm{p}=0.037 \uparrow\end{array}$ \\
\hline visit \#2 to visit \#4 & 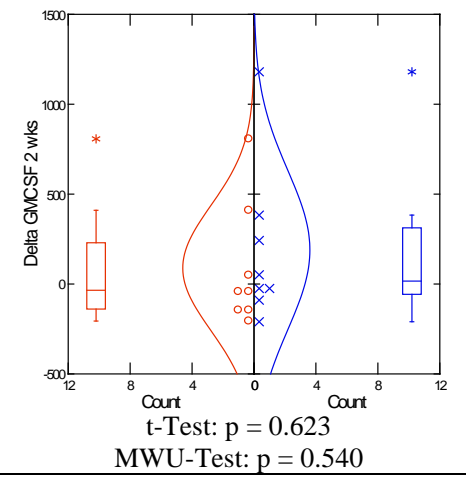 & 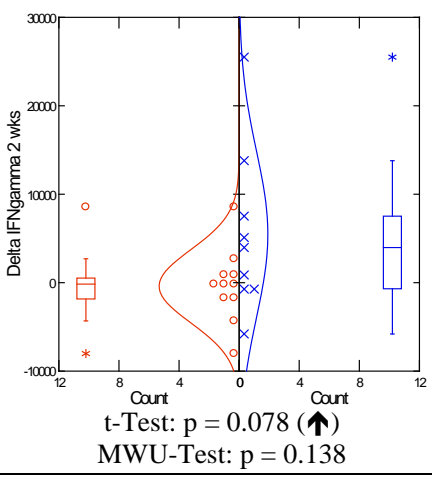 & 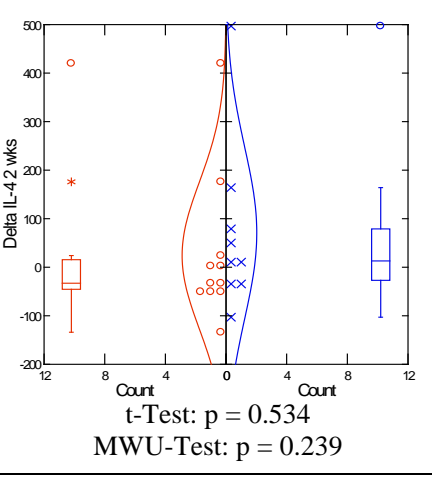 \\
\hline visit \#4 to visit \#5 & 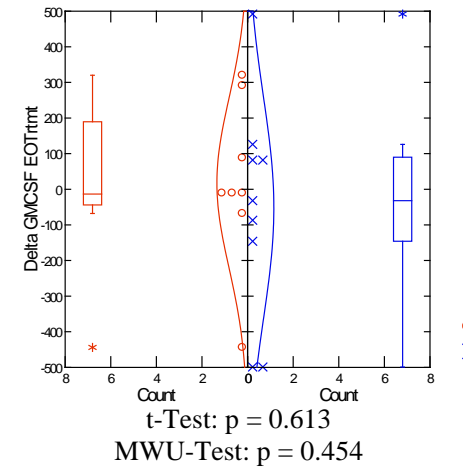 & 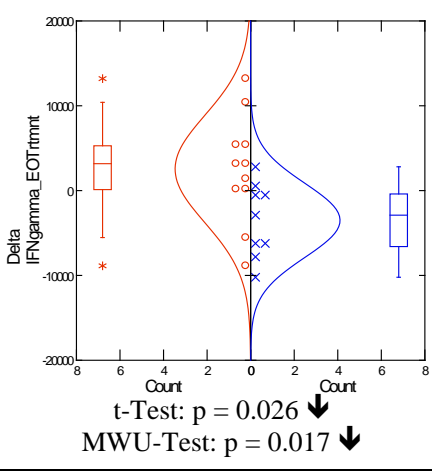 & 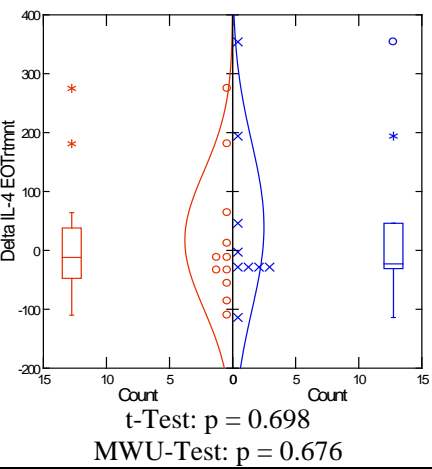 \\
\hline
\end{tabular}

Figure 2. GM-CSF (a), IFN $\gamma$ (b), and IL-4 (c) release in stimulated whole-blood cultures. Comparison of placebo and CA group, upper panels = delta response after 3 days of treatment (visit \#3-baseline visit \#2); center panels = delta response visit \#4 (14 days of treatment)—baseline, lower panels = delta response visit \#5 (2 - 4 days after end of treatment)—visit \#4. MWU = Mann Whitney U Test. $\uparrow=$ stimulated, $\downarrow$ = inhibited; red circles: placebo group; blue cross: CA treatment. 


\begin{tabular}{|c|c|c|c|}
\hline Changes from & a) IL-10 (Test for unpaired samples) & b) IL-17 (Test for unpaired samples) & c) TNF $\boldsymbol{B}$ (Test for unpaired samples) \\
\hline visit \#2 to visit \#3 & 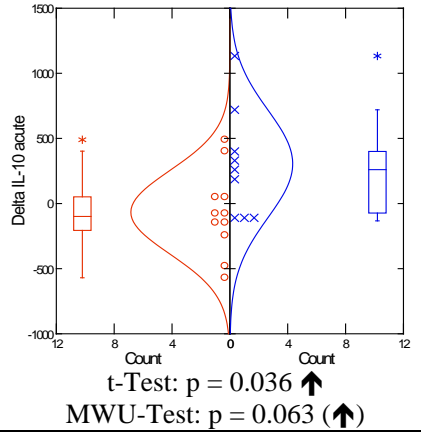 & 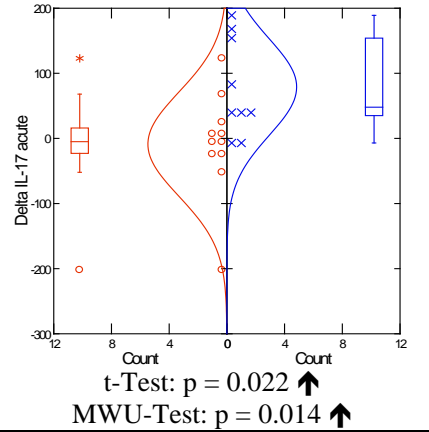 & $\begin{array}{c}{ }_{10}^{\text {Count }}{ }^{5} \\
\text { t-Test: } \mathrm{p}=0.018 \text { Count }^{10} \\
\text { MWU-Test: } \mathrm{p}=0.006 \uparrow\end{array}$ \\
\hline visit \#2 to visit \#4 & $\begin{array}{c}\text { MWU-Test: } \mathrm{p}=0.020 \uparrow \\
\text { cont }{ }^{4}\end{array}$ & 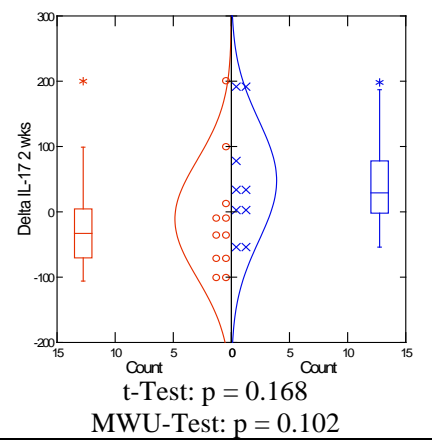 & 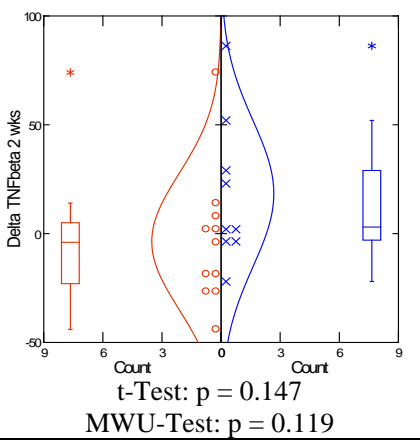 \\
\hline visit \#4 to visit \#5 & $\begin{array}{c}{ }^{6} \text { count }^{3}{ }_{0}{ }^{3} \text { cant }^{6} \\
\text { t-Test: } \mathrm{p}=0.692 \\
\text { MWU-Test: } \mathrm{p}=0.970\end{array}$ & 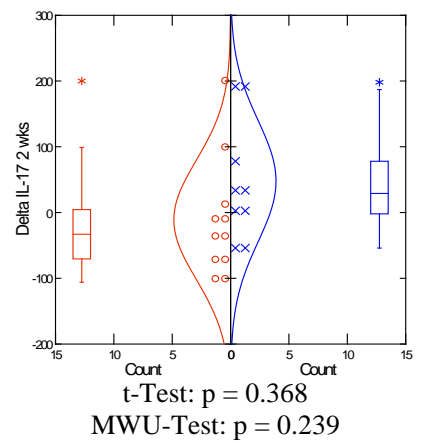 & $\begin{array}{l}{ }_{-100}^{8} \text { Count }^{4}{ }^{4}{ }^{4}{ }^{4} \text { count }^{8} \\
\text { t-Test: } \mathrm{p}=0.155{ }^{8} \\
\text { MWU-Test: } \mathrm{p}=0.119\end{array}$ \\
\hline
\end{tabular}

Figure 3. IL-10 (a), IL-17 (b), and TNF $\beta$ (c) release in stimulated whole-blood cultures. Comparison of placebo and CA group, upper panels = delta response after 3 days of treatment (visit \#3-baseline visit \#2); center panels = delta response visit \#4 (14 days of treatment) - baseline, lower panels = delta response visit \#5 (2 - 4 days after end of treatment)-visit \#4. MWU = Mann Whitney U Test. $\uparrow=$ stimulated, $\downarrow$ = inhibited; red circles: placebo group; blue cross: CA treatment.

The cytokines indicating significant immunomodulatory effects by CA treatment can all be related to T-lymphocyte activities: GM-CSF, IFN $\gamma$, IL-4, IL-10, IL-17, as well as TNF $\beta$ (see Figures 2 and 3). All of these cytokines were found increased in the culture supernatants of these donors when comparing visit \#2 (baseline, immediately before starting CA ingestion) to visit \#3 (after 3 days of CA ingestion). For IFN $\gamma$ the difference between visits \#4 and \#5 showed a significant reduction in the stimulated release of this cytokine compared to placebo (Figure 2).

There was only one mediator, IL-10, for which a significant increase in its release could still be detected also at visit \#4 (day 14 of CA treatment, see Figure 3).

\subsection{Safety and Tolerability}

All measured clinical parameters, body weight, temperature, heart rate and blood pressure remained almost constant during the study, with no significant differences between the two study populations (data not shown). The global assessment of tolerability for both treatments was rated at the end of the study. Both investigators and subjects rated the tolerability of CA or placebo in $100 \%$ of the cases as beeing "good" or "very good" $(p=1.00 ; p=$ 1.00 , respectively). Only one of the 20 participants reported an adverse event (headache of moderate intensity), 
which was considered to be not related to the intake of the investigational product.

\section{Discussion}

The clinical study presented above was performed to investigate immunomodulatory properties, potentially related to the ingestion of a concentrated juice (CA) a preparation of fruits, vegetables, mushrooms, oils and numerous other ingredients (80 different in total).

Usually, such products are mainly thought to exert rather non-specific effects via either improving the supply of vitamins, or the presence of antioxidants. Despite the fact that in the CA juice tested in this clinical trial surely considerable amount of vitamins and antioxidants (such as polyphenols, flavonoids, etc.) are present, it would be inadequate to assume that these alone could have caused the changes observed during this study. For example, other constituents are well-known for their effects on immune cells, such as docohexaenoic acid (DHA) from Shizochytrium sp. [23], selenium [24], L-carnitine [25], zinc [26], etc. Multi-component mixtures of biologically active constituents, like CA, must indeed be expected to potentially generate more complex interactions with human physiology. Each constituent may show effects on different sub-systems of the human body (e.g. on mucosal secretions, the mucosal epithelial cells, various organs, immune cells, the neuro-endocrine system, but also-last, but surely not least-the intestinal microbiota, which again can generate additional secondary effects). Thus, the more complex such mixtures, the less likely it will be possible to trace back certain effects to just one of these ingredients. In the end, preparations like CA can only be judged by their net effects on certain physiological functions in vivo. It was therefore the purpose of this clinical investigation to examine possible shifts in immune cell activation as a measure of what the ingestion of CA may change with regards to defense reactions or inflammatory processes.

The current results indicated little or no effect on the innate part of the human immune system in vivo, but rather suggested T-cells to mainly benefit from CA intake. This was rather surprising, because the typical immunomodulators of herbal origin, such as Echinacea, so far were described to exert their effects predominantly via improving functions of cells of the innate immune system, such as macrophages [27], which could also be confirmed by clinical trials [28]. One of the biggest advantages of testing substance effects ex vivo after oral ingestion is that this application route usually eliminates the risk for artificial immune cell activation by LPS, which is not only a common (but harmless upon ingestion) contaminant of natural preparations. In addition, it is one of the most powerful leukocyte-activating agents, belonging to the pathogen-associated molecular pattern (PAMP) molecules. During normal gut passage the intestinal epithelia potently block bacterial endotoxins from triggering inflammatory responses, unless gut leakage occurs or high-fat meals are consumed [29]. In in vitro experiments such molecules often mimic or even override potential effects generated by the plant-specific compounds [30].

The whole-blood culture model used in these experiments to detect immunomodulatory activities of CA made it possible to investigate immunomodulatory effects ex vivo under in vivo-like, pathophysiologically relevant conditions. The latter were established by using pro-inflammatory activators, triggering immune cell responses similar to those seen during infectious diseases (by combining the monocyte activator LPS, a polyclonal T-cell stimulant SE-B and a co-stimulatory antibody, anti-CD28). By means of this a moderate, physiological (=combined) activation of different leukocyte populations was achieved that was able to reliably show both, stimulating as well as inhibitory activities of CA ingredients. Although these experiments were performed using a relatively small group of volunteers $(n=20$ in both, the verum and the placebo group), the activity profile demonstrated a relatively clear picture: All cytokines that showed significant changes following CA ingestion (GM-CSF, IFN $\gamma$, IL-4, IL-10, IL-17, TNF $\beta$ ) can be assigned to different T-cell subsets [31]. Except for IL-10 (see below), all other cytokines peaked on day 3 of treatment (compared to baseline on day 0). The kinetics suggest that soon after starting CA ingestion, the T-lymphocytes respond more efficiently to stimulation (mode of action so far unknown). When tested again after 14 days of treatment, this enhancing effect for GM-CSF, IFN $\gamma$, IL-4, IL-17, and TNF $\beta$ could not be detected anymore.

Instead, when activated experimentally again after 2 weeks of taking CA, the formation of IL-10 seems to still be upregulated in this phase of CA treatment. IL-10 can either be produced by leukocytes of the innate part of the immune system, or certain T-lymphocytes. However, none of the other marker cytokines of the innate immune cells (IL- 1, TNF $\alpha$, IL-6, etc.) was affected by CA treatment. It seems therefore reasonable to assume that the secretion of this inhibitory cytokine was either generated by helper $\mathrm{T}$ cells of type 2 (Th2; [32]) or regulatory $\mathrm{T}$ cells (Treg; [33]). These latter two are also known to be delayed in their course of activation compared to Th1 and Th17 cells, which must be regarded the source for the additional amounts of GM-CSF, IFN $\gamma$, IL-17, and TNF $\beta$ found in the supernatants of CA treated individuals after 3 days of ingestion. The only other Th2 cytokine that responded to CA application was IL-4, although this was found increased on visit \#3 only. 
The fact that for IFN $\gamma$ a significant withdrawal effect was observed at visit \#5 can be regarded another sign of CA acting mainly on T cells.

As IL-10 is one of the few cytokines that do have anti-inflammatory (downregulating) activity, these results suggest a real modulatory effect by CA in that it improves the capacities of immune cells to secrete, upon activation, both, pro- and anti-inflammatory mediators. Moreover, IL-10 does have additional functions in the terminal differentiation of germinal center B cells into immunoglobulin-secreting plasma cells. Thus, it may be speculated that CA, in a more indirect manner, may also help setting up antigen-specific production of antibodies [34]. This could easily be investigated in a next clinical study measuring antibody titers in vaccinated volunteers treated with CA compared to placebo.

The small study population is a limitation of this study. Therefore these results can only be regarded as preliminary results and have to be confirmed in a larger study population.

Nevertheless, these results indicate a clear correlation between the ingestion of CA and the changes in immune cell activities in healthy volunteers as tested by wholeblood assays. These effects seem to result in an enhanced response of T-lymphocytes to activation as it occurs in infectious diseases. The very low rate of adverse events together with the overall good compliance demonstrates the safety and the consumers' acceptance of the study product.

\section{Acknowledgements}

The study was funded by Hans-Günter Berner GmbH \& Co. KG (Altenholz; Germany).

\section{Conflict of Interests}

M. Schmolz has done the analytical work with the TruCulture ${ }^{\circledR}$ system and has mainly written the manuscript; R. März has done the data evaluation and the statistics; M. Schaudt was mainly involved in the project management of the study; C. Schaudt: was mainly involved in the planning the study; C. Lauster was the primary investigator of the study.

\section{REFERENCES}

[1] J. L. Rios, M. C. Recio, J. M. Escandell and I. Andujar, "Inhibition of Transcription Factors by Plant-Derived Compounds and Their Implications in Inflammation and Cancer," Current Pharmaceutical Design, Vol. 15, No. 11, 2009, pp. 1212-1237. http://dx.doi.org/10.2174/138161209787846874

[2] S. A. Stanner, J. Hughes, C. N. Kelly and J. Buttriss, “A Review of the Epidemiological Evidence for the 'Anti- oxidant Hypothesis'," Public Health Nutrition, Vol. 7, No. 3, 2004, pp. 407-422. http://dx.doi.org/10.1079/PHN2003543

[3] M. Dell’Agli, C. Di Lorenzo, M. Badea, E. Sangiovanni, L. Dima, E. Bosisio and P. Restani, "Plant Food Supplements with Anti-Inflammatory Properties: A Systematic Review (I)," Critical Reviews in Food Science and Nutrition, Vol. 53, No. 4, 2013, pp. 403-413.

http://dx.doi.org/10.1080/10408398.2012.682123

[4] C. Di Lorenzo, M. Dell'agli, E. Colombo, E. Sangiovanni and P. Restani, "Metabolic Syndrome and Inflammation: A Critical Review of in Vitro and Clinical Approaches for Benefit Assessment of Plant Food Supplements," Evidence-Based Complementary and Alternative Medicine, Vol. 2013, 2013, Article ID: 782461.

[5] N. Iyer, S. A. Marathe, D. Chaudhuri, P. Garai and D. Chakravortty, "Immunomodulation Using Agonists and Antagonists: Potential Clinical Applications,” Expert Opinion on Investigational Drugs, Vol. 21, No. 1, 2012, pp. 67-81. http://dx.doi.org/10.1517/13543784.2012.642367

[6] J. M. van Dieren, E. J. Kuipers, J. N. Samsom, E. E. Nieuwenhuis and C. J. van der Woude, "Revisiting the Immunomodulators Tacrolimus, Methotrexate, and Mycophenolate Mofetil: Their Mechanisms of Action and Role in the Treatment of IBD," Inflammatory Bowel Diseases, Vol. 12, No. 4, 2006, pp. 311-327. http://dx.doi.org/10.1097/01.MIB.0000209787.19952.53

[7] M. Ramadan, S. Goeters, B. Watzer, E. Krause, K. Lohmann, R. Bauer, B. Hempel and P. Imming, "Chamazulene Carboxylic Acid and Matricin: A Natural Profen and Its Natural Prodrug, Identified through Similarity to Synthetic Drug Substances," Journal of Natural Products, Vol. 69, No. 7, 2006, pp. 1041-1045.

http://dx.doi.org/10.1021/np0601556

[8] V. M. Chandrashekhar, K. S. Halagali, R. B. Nidavani, M. H. Shalavadi, B. S. Biradar, D. Biswas and I. S. Muchchandi, "Anti-Allergic Activity of German Chamomile (Matricaria recutita L.) in Mast Cell Mediated Allergy Model,” Journal of Ethnopharmacology, Vol. 137, No. 1, 2011, pp. 336-340.

http://dx.doi.org/10.1016/j.jep.2011.05.029

[9] X. Gao, D. Deeb, Y. Liu, S. Gautam, S. A. Dulchavsky and S. C. Gautam, "Immunomodulatory Activity of Xanthohumol: Inhibition of T Cell Proliferation, Cell-Mediated Cytotoxicity and Th1 Cytokine Production through Suppression of NF-KappaB,” Immunopharmacology and Immunotoxicology, Vol. 31, No. 3, 2009, pp. 477-484. http://dx.doi.org/10.1080/08923970902798132

[10] U. Svajger and M. Jeras, “Anti-Inflammatory Effects of Resveratrol and Its Potential Use in Therapy of Immune-Mediated Diseases," International Reviews of Immunology, Vol. 31, No. 3, 2012, pp. 202-222. http://dx.doi.org/10.3109/08830185.2012.665108

[11] J. H. Park, J. W. Kim, C. M. Lee, Y. D. Kim, S. W. Chung, I. D. Jung, K. T. Noh, J. W. Park, D. R. Heo, Y. K. Shin, J. K. Seo and Y. M. Park, "Sulforaphane Inhibits the Th2 Immune Response in Ovalbumin-Induced Asthma,” BMB Reports, Vol. 45, No. 5, 2012, pp. 311-316. http://dx.doi.org/10.5483/BMBRep.2012.45.5.311 
[12] Y. Zhang, D. Y. Leung, B. N. Richers, Y. Liu, L. K. Remigio, D. W. Riches and E. Goleva, "Vitamin D Inhibits Monocyte/Macrophage Proinflammatory Cytokine Production by Targeting MAPK Phosphatase-1,” Journal of Immunology, Vol. 188, No. 5, 2012, pp. 2127-2135. http://dx.doi.org/10.4049/jimmunol.1102412

[13] J. M. Carcamo, O. Borquez-Ojeda and D. W. Golde, "Vitamin C Inhibits Granulocyte Macrophage-Colony-Stimulating Factor-Induced Signaling Pathways,” Blood, Vol. 99, No. 9, 2002, pp. 3205-3212. http://dx.doi.org/10.1182/blood.V99.9.3205

[14] C. Hartel, T. Strunk, P. Bucsky and C. Schultz, "Effects of Vitamin C on Intracytoplasmic Cytokine Production in Human Whole Blood Monocytes and Lymphocytes," Cytokine, Vol. 27, No. 4-5, 2004, pp. 101-106. http://dx.doi.org/10.1016/j.cyto.2004.02.004

[15] J. J. Casciari, H. D. Riordan, N. Mikirova and J. Austin, "Effect of Vitamin C Supplementation on ex Vivo Immune Cell Functioning," Journal of Orthomolecular Medicine, Vol. 18, No. 2, 2003, pp. 83-92.

[16] J. Tamura, K. Kubota, H. Murakami, M. Sawamura, T. Matsushima, T. Tamura, T. Saitoh, H. Kurabayshi and T. Naruse, "Immunomodulation by Vitamin B12: Augmentation of CD8+ T Lymphocytes and Natural Killer (NK) Cell Activity in Vitamin B12-Deficient Patients by Methyl-B12 Treatment," Clinical \& Experimental Immunology, Vol. 116, No. 1, 1999, pp. 28-32. http://dx.doi.org/10.1046/j.1365-2249.1999.00870.x

[17] H. K. Kwak, C. M. Hansen, J. E. Leklem, K. Hardin and T. D. Shultz, "Improved Vitamin B-6 Status Is Positively Related to Lymphocyte Proliferation in Young Women Consuming a Controlled Diet,” Journal of Nutrition, Vol. 132, No. 11, 2002, pp. 3308-3313.

[18] S. C. Mueller, R. Marz, M. Schmolz and B. Drewelow, "Intraindividual Long Term Stability and Response Corridors of Cytokines in Healthy Volunteers Detected by a Standardized Whole-Blood Culture System for Bed-Side Application,” BMC Medical Research Methodology, Vol. 12, 2012, p. 112.

[19] M. Triantafilou and K. Triantafilou, "Lipopolysaccharide Recognition: CD14, TLRs and the LPS-Activation Cluster," Trends in Immunology, Vol. 23, No. 6, 2002, pp. 301-304. http://dx.doi.org/10.1016/S1471-4906(02)02233-0

[20] T. Nagashima, T. Aranami, C. Iclozan and K. Onoé, "Analysis of T Cell Responses to a Superantigen, Staphylococcal Enterotoxin-B," Journal of Clinical and Experimental Hematopathology, Vol. 44, No. 1, 2004, pp. 25-32. http://dx.doi.org/10.3960/jslrt.44.25

[21] M. E. van Berkel and M. A. Oosterwegel, "CD28 and ICOS: Similar or Separate Costimulators of T Cells?” Immunology Letters, Vol. 105, No. 2, 2006, pp. 115-122. http://dx.doi.org/10.1016/j.imlet.2006.02.007

[22] M. M. Wurfel, W. Y. Park, F. Radella, J. Ruzinski, A. Sandstrom, J. Strout, R. E. Bumgarner and T. R. Martin, "Identification of High and Low Responders to Lipopolysaccharide in Normal Subjects: An Unbiased Approach to Identify Modulators of Innate Immunity,” Journal of
Immunology, Vol. 175, No. 4, 2005, pp. 2570-2578.

[23] N. Serhan, "Resolvins and Protectins: Novel Lipid Mediators in Anti-Inflammation and Resolution," Scandinavian Journal of Food and Nutrition, Vol. 50, No. S2, 2006, pp. 68-78.

http://dx.doi.org/10.1080/17482970601066298

[24] Z. Huang, A. H. Rose and P. R. Hoffmann, "The Role of selenium in Inflammation and Immunity: From Molecular Mechanisms to Therapeutic Opportunities,” Antioxidants \& Redox Signaling, Vol. 16, No. 7, 2012, pp. 705-743. http://dx.doi.org/10.1089/ars.2011.4145

[25] G. Fortin, "L-Carnitine and Intestinal Inflammation,” Vitamins \& Hormones, Vol. 86, 2011, pp. 353-366.

[26] H. Haase and L. Rink, "Zinc Signals and Immune Function,” Biofactors, 2013.

[27] A. M. Sullivan, J. G. Laba, J. A. Moore and T. D. Lee, "Echinacea-Induced Macrophage Activation," Immunopharmacology and Immunotoxicology, Vol. 30, No. 3, 2008, pp. 553-574.

http://dx.doi.org/10.1080/08923970802135534

[28] M. R. Ritchie, J. Gertsch, P. Klein and R. Schoop, "Effects of Echinaforce (R) Treatment on ex Vivo-Stimulated Blood Cells,” Phytomedicine, Vol. 18, No. 10, 2011, pp. 826-831. http://dx.doi.org/10.1016/j.phymed.2011.05.011

[29] A. P. Moreira, T. F. Texeira, A. B. Ferreira, C. Peluzio Mdo and C. Alfenas Rde, "Influence of a High-Fat Diet on Gut Microbiota, Intestinal Permeability and Metabolic Endotoxaemia," British Journal of Nutrition, Vol. 108, No. 5, 2012, pp. 801-809. http://dx.doi.org/10.1017/S0007114512001213

[30] N. D. Pugh, C. R. Jackson and D. S. Pasco, “Total Bacterial Load within Echinacea Purpurea, Determined Using a New PCR-Based Quantification Method, Is Correlated with LPS Levels and in Vitro Macrophage Activity," Planta Medica, Vol. 79, No. 1, 2013, pp. 9-14.

[31] T. R. Mosmann and S. Sad, "The Expanding Universe of T-Cell Subsets: Th1, Th2 and More,” Immunology Today, Vol. 17, No. 3, 1996, pp. 138-146. http://dx.doi.org/10.1016/0167-5699(96)80606-2

[32] E. Maier, A. Duschl and J. Horejs-Hoeck, "STAT6-Dependent and -Independent Mechanisms in Th2 Polarization,” European Journal of Immunology, Vol. 42, No. 11, 2012, pp. 2827-2833.

http://dx.doi.org/10.1002/eji.201242433

[33] T. L. Geiger and S. Tauro, "Nature and Nurture in Foxp3(+) Regulatory T Cell Development, Stability, and Function,” Human Immunology, Vol. 73, No. 3, 2012, pp. 232-239.

http://dx.doi.org/10.1016/j.humimm.2011.12.012

[34] S. O. Yoon, X. Zhang, P. Berner and Y. S. Choi, "IL-21 and IL-10 Have Redundant Roles but Differential Capacities at Different Stages of Plasma Cell Generation from Human Germinal Center B Cells,” Journal of Leukocyte Biology, Vol. 86, No. 6, 2009, pp. 1311-1318. http://dx.doi.org/10.1189/jlb.0409268 


\author{
Abbreviations \\ BDNF: Brain-derived neurotrophic factor \\ Eotaxin: Eotaxin \\ tor \\ ICAM-1: Intercellular adhesion molecule-1 \\ IFN- $\gamma$ : Interferon gamma \\ IL- $1 \alpha$ : Interleukin-1 alpha \\ IL-1 $\beta$ : Interleukin- 1 beta \\ IL-1ra: Interleukin-1 receptor antagonist \\ IL-2: Interleukin-2 \\ IL-3: Interleukin-3 \\ IL-4: Interleukin-4 \\ IL-5: Interleukin-5 \\ IL-6: Interleukin-6 \\ IL-7: Interleukin-7
}

GM-CSF: Granulocyte/monocyte colony-stimulating fac-
IL-8: Interleukin-8

IL-10: Interleukin-10

IL-12p40: Interleukin-12 p40

IL-12p70: Interleukin-12 p70

IL-15: Interleukin-15

IL-17: Interleukin-17

IL-23: Interleukin-23

MCP-1: Monocyte chemoattractant protein-1

MIP-1 $\alpha$ : Macrophage inflammatory protein- 1 alpha

MIP-1 $\beta$ : Macrophage inflammatory protein- 1 beta

MMP-3: Matrix metalloproteinase-3

SCF: Stem cell factor

TNF $\alpha$ : Tumour necrosis factor alpha

TNF $\beta$ : Tumour necrosis factor beta

VEGF: Vascular endothelial growth factor 